\title{
Energy Mechanism of Rock Burst in the Rock-Coal Combined Body
}

\author{
Shaojie Chen \\ State Key Laboratory of Mine Disaster \\ Prevention and Control \\ Shandong University of Science and \\ Technology \\ Qingdao, China \\ chensj@sdust.edu.cn
}

\author{
Zhen Zhang \\ State Key Laboratory of Mine Disaster \\ Prevention and Control \\ Shandong University of Science and \\ Technology \\ Qingdao, China \\ 2954163563@qq.com
}

\author{
Dawei Yin \\ State Key Laboratory of Mine Disaster \\ Prevention and Control \\ Shandong University of Science and \\ Technology \\ Qingdao, China, Corresponding author, \\ 949251142@qq.com
}

DongMei Huang

State Key Laboratory of Mine Disaster

Prevention and Control

Shandong University of Science and Technology

Qingdao, China

kmcandy@126.com

\author{
Ning Jiang \\ State Key Laboratory of Mine Disaster \\ Prevention and Control \\ Shandong University of Science and \\ Technology \\ Qingdao, China \\ 150653034@qq.com
}

Abstract-Rock burst hazards during deep mining are a dynamic phenomenon of the sudden release of elastic energy aggregated in the roof rock-coal combined body. In this paper, the occurrence mechanism of rock burst for roof rock-coal combined body was studied through energy dissipation theory. And the elastic energy attenuation degree of combined body was defined. Additionally, the effects of height ratio of roof rock to coal and elastic modulus of roof rock or coal on the rock burst were analyzed in the potentiality of the combined body. Results show that the elastic energy attenuation degree is positively correlated with the equivalent elastic modulus of combined body. And the equivalent elastic modulus is shown to a positive correlation with the height ratio of roof rock to coal and elastic modulus of roof rock or coal. Generally, the larger the height ratio and elastic modulus of roof rock or coal are, the great the equivalent elastic modulus is and the stronger the elastic energy attenuation degree is. And the roof rock-coal combined body easily occurs in rock burst. The above achievements are of great significance to understand the elastic energy attenuation characteristics and to prevent rock burst hazards of the roof rock-coal combined body.

Keywords-rock burst hazards, roof rock-coal combined body, elastic energy attenuation degree, equivalent elastic modulus; height ratio of roof rock to coal, elastic modulus of roof rock or coal

\section{INTRODUCTION}

With the depletion of shallow coal resources, it is necessary to develop the deep coal resources in China. However, frequent dynamic hazards can be induced by the complex geological conditions and high stress environment in deep coal mine, such as rock burst, coal bump, gas outburst and floor heave, causing huge economic losses and casualties [1-2]. Among them, rock burst is a typical dynamic disaster during deep mining. In order to prevent and control the rock burst hazards effectively, it is essential to analyze the occurrence mechanism of rock burst in deep mining.

Many engineering applications show that rock burst hazards in deep mining generally caused by the structural instability and damage of the roof rock-coal combined body [3-5]. And the rock burst occurrence mechanism for the roof rock-coal combined body has been studied by many domestic and foreign scholars and they have obtained many interesting results. Through the slippery theory, the occurrence mechanism of rock burst for the roof rock-coal combined body was studied by Qi et al [6]. Lu et al. found that the rock burst can be induced by the hard roof rock fall [4]. Li et al. proposed that the rock burst potentiality of the roof rock-coal combined body was larger than that of the single coal or rock [7]. What's more, the effects of height ratio of roof rock to coal, roof rock strengths, homogeneity, and interface angles [3] on the rock burst potentiality of combined body were researched. Lu et al. studied the rock burst tendency of evolution and acoustic-electromagentic effects of compound coal-rock samples [8]. In addition, the strength and failure characteristics of the roof rock-coal combined bodies under uniaxial compression [5, 9-10], cyclic loading and unloading [11] and tri-axial compression [3] were studied.

The above achievements have important significance for understanding the occurrence mechanism of rock burst for the roof rock-coal combined body. Meanwhile, due to the complexity of rock mechanics in deep mining, there are many factors that affect the rock burst occurrence. Further researches are needed on the occurrence mechanism of rock burst in deep mining. Based on these, in this paper, the occurrence mechanism of rock burst for the roof rock-coal combined body was studied through energy dissipation theory. And the effects of height ratio of roof rock to coal and elastic modulus of roof rock or coal on the rock burst potentiality of the combined body were discussed and analyzed.

\section{ENERGY DISSIPATION ANALYSIS ON ROCK BURST OCCURRENCE IN ROCK-COAL COMBINED BODY}

Under the influence of coal mining, the balance of system consisted of energy consumption and external energy input is formed in the roof rock-coal combined body. Firstly, the roof 
rock and coal in the combined body occur elastic deformation and the energy input from the outside is aggregated in them as elastic energy. Generally, the strength and elastic modulus of the roof rock is larger than coal. Thus, the coal first occurs inelastic deformation. While, the roof rock may still be in the elastic deformation stage or occurs smaller inelastic deformation. A little bit of energy input from the outside is consumed. But most of energy input from the outside is still aggregated in the roof rock and coal of the combined body. Then the coal takes the lead in reaching the ultimate limit state and destroyed, and the elastic energy in coal released. And now the roof rock rebounds, and the elastic energy aggregated in the roof rock is released and acted on coal, aggravating the impact failure of coal. The rock burst of combined body occurs.

The rock burst is a dynamic phenomenon of the sudden release of the elastic energy aggregated in the roof rock-coal combined body. And this process occurs in the residual deformation stage of the loaded combined body [12]. Therefore, the elastic energy attenuation degree can be taken as a evaluation index for the rock burst occurrence for the roof rock-coal combined body.

The elastic strain energy of roof rock-coal combined body under uniaxial compression is

$$
U=\frac{1}{2} \sigma \varepsilon_{e}=\frac{\sigma^{2}}{2 E}
$$

Where, $U$ is the elastic strain energy of the combined body; $E$ is the equivalent elastic modulus of the combined body; $\varepsilon_{e}$ is the elastic strain of the combined body; $\sigma$ is the axial stress, which is [13-14]

$$
\sigma=E \varepsilon \exp \left[-\left(\frac{\varepsilon}{\varepsilon_{0}}\right)^{m}\right]
$$

Where, $\varepsilon$ is the total strain of the combined body; $\varepsilon_{0}$ is the distribution scale of Weibull distribution; $m$ is the morphological parameter characterized in the form of strain [13].

The elastic strain energy $U$ is determined by solving the resulting equations of Eq. (1)-(2) simultaneous,

$$
U=\frac{1}{2} \sigma \varepsilon_{e}=\frac{E \varepsilon^{2} \exp \left[-2\left(\frac{\varepsilon}{\varepsilon_{0}}\right)^{m}\right]}{2}
$$

Therefore, the elastic energy attenuation degree $\eta$ is

$$
\eta=\frac{\partial U}{\partial \varepsilon}=\frac{\sigma}{E} \frac{\partial \sigma}{\partial \varepsilon}=E \varepsilon\left[1-m\left(\frac{\varepsilon}{\varepsilon_{0}}\right)^{m}\right] \exp \left[-2\left(\frac{\varepsilon}{\varepsilon_{0}}\right)^{m}\right]
$$

As $m$ taken as 1, the Eq. (4) can be changed as [15].

$$
\eta=\frac{\partial U}{\partial \varepsilon}=\frac{\sigma}{E} \frac{\partial \sigma}{\partial \varepsilon}=E \varepsilon\left[1-\frac{\varepsilon}{\varepsilon_{0}}\right] \exp \left[-2 \frac{\varepsilon}{\varepsilon_{0}}\right]
$$

In Eq. (5), it can be seen that $\eta$ is positively correlated with $E$. That means the larger the equivalent elastic modulus is, the greater the elastic energy attenuation degree is. And the roof rock-coal combined body occurs rock burst easily.
In order to obtain $E$, a mechanical model for roof rockcoal combined body was established, as shown in Fig. 1. In Fig. 1, $L r$ and $L c$ are the heights of roof rock and coal, respectively. And $L$ is the height of combined body. $\sigma_{1}$ is the axial stress loaded by the combined body.

The axial strains of roof rock, coal and combined body are

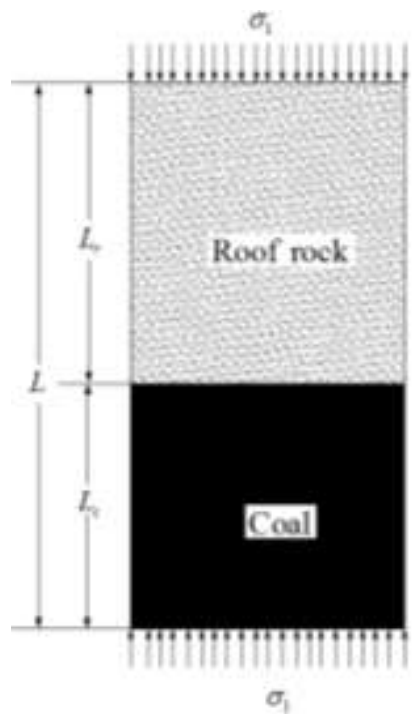

Fig. 1. A mechanical model for roof rock-coal combined body

$$
\left\{\begin{array}{l}
\varepsilon_{r}=\frac{\sigma_{r 1}}{E_{r}} \\
\varepsilon_{c}=\frac{\sigma_{c 1}}{E_{c}} \\
\varepsilon=\frac{\sigma_{1}}{E}
\end{array}\right.
$$

Where, $\varepsilon_{r}$ and $\varepsilon_{c}$ are the axial strains of roof rock and coal, respectively. $E_{r}$ and $E_{c}$ are the elastic modulus of roof rock and coal, respectively. $\sigma_{r 1}$ and $\sigma_{c 1}$ are the axial stresses of roof rock and coal, respectively.

It is assumed that the roof rock and coal are tightly bonded together. And the interface deformation between roof rock and coal is ignored. According to the static equilibrium and superposition principle, it can be seen that

$$
\left\{\begin{array}{l}
\sigma_{1}=\sigma_{r 1}=\sigma_{c 1} \\
\varepsilon_{r} \neq \varepsilon_{c} \\
\varepsilon=\varepsilon_{r}+\varepsilon_{c}
\end{array}\right.
$$

Also, the axial deformation of the roof rock-coal combined body is

$$
\varepsilon L=\varepsilon_{r} L_{r}+\varepsilon_{c} L_{c}
$$

Therefore, the equivalent elastic modulus of the combined body can be obtained by solving the resulting equations of Eqs. (6)-(8) simultaneously,

$$
E=\frac{E_{r} E_{c} L}{E_{c} L_{r}+E_{r} L_{c}}
$$


In Eq. (9), it an be seen that $E$ is determined by the heights and elastic moduli of roof rock and coal. And that means the height ratio and elastic moduli affect the the elastic energy attenuation degree and further influence the rock burst potentiality of roof rock-coal body. And these effects are analyzed as follow.

\section{EFFECTS OF HEIGHT RATIO AND Elastic Moduli OF ROOF ROCK AND COAL ON ROCK BURST POTENTIALITY OF COMBINED BODY}

\section{A. Effect of height ratio of roof rock to coal on rock} burst potentiality of combined body

The Eq. (9) can be changed as

$$
\frac{1}{E}=\frac{L_{r}}{E_{r} L}+\frac{L_{c}}{E_{c} L}
$$

And,

$$
L=L_{c}+L_{r}
$$

Thus,

$$
\frac{1}{E}=\frac{1}{E_{r}}+\left(\frac{1}{E_{c}}-\frac{1}{E_{r}}\right) \frac{1}{1+\frac{L_{r}}{L_{c}}}
$$

In Eq. (12), under the same condition, $E$ is positively correlated with the height ratio of roof rock to coal. These results are basically consistent with previous experimental and numerical simulation studies [10], as shown in Fig. 2. And this illustrates that the larger the height ratio is, the great the equivalent elastic modulus is, and the stronger the elastic energy attenuation degree is. Therefore, the rock burst is easy for the roof rock-coal combined body to occur.

There are many evaluating indicators to evaluate the rock burst potentiality of coal, as shown in Table I, mainly including the dynamic failure time $D_{T}$, elastic energy index $W_{E T}$ and bursting energy index $K_{E}$. And one or more evaluating indicator can be used to evaluate the rock burst potentiality of the roof rock-coal combined body. Taken $K_{E}$ as an evaluating indicator, Lu analyzed the effects of height ratio on rock burst potentialities of roof rock-coal combined body, as shown in Fig. 3 [15]. Through the cyclic loading test, Song et al. analyzed the rock burst potentiality of roof rock-coal combined bodies with height ratios of 1:1 and 2:1, such as $D_{T}, W_{E T}$ and $K_{E}$, as shown in Table II [16]. And using $\mathrm{PFC}^{2 \mathrm{D}}$ software, the uniaxial compression tests on combined bodies with different height ratios were conducted by Guo et al. [17]. And they evaluated the rock burst potentialities of the combined bodies with different height ratios based on $K_{E}$, as shown in Table 3 .

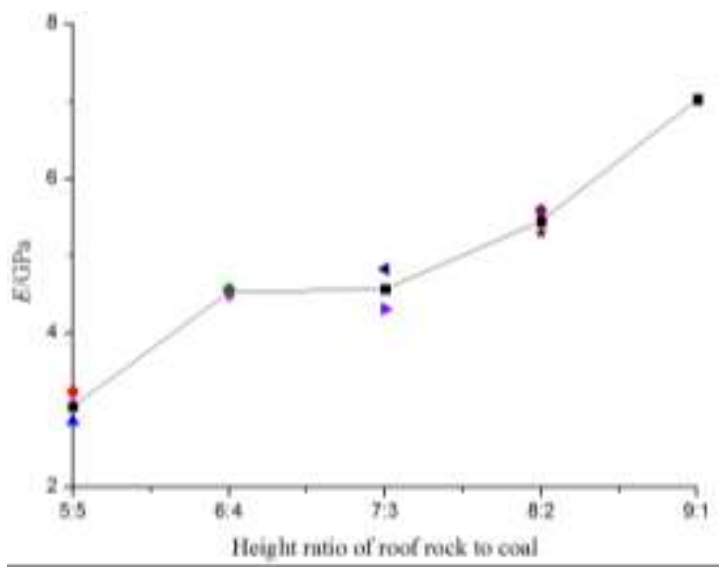

Fig. 2. Relationship between elastic modulus and the height ratio of roof rock to coal [10]

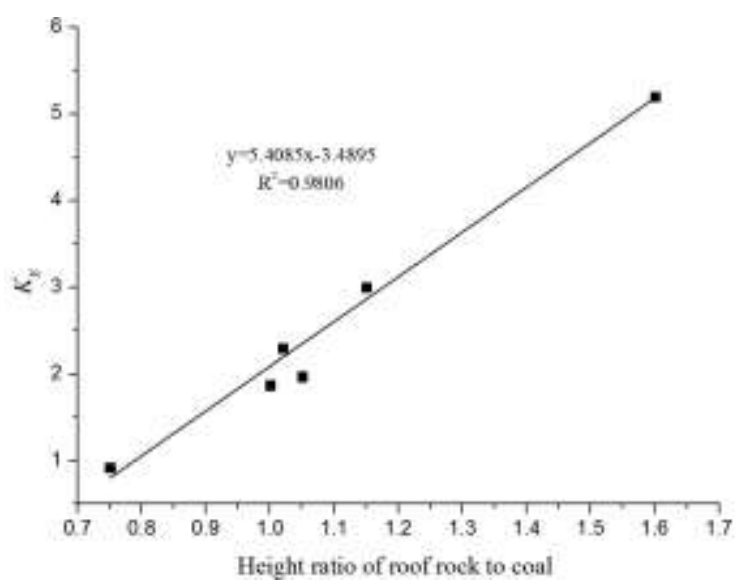

Fig. 3. Relationship between $K_{E}$ and height ratio of roof rock to coal [15]

TABLE I. ROCK BURST POTENTIALITY CLASSIFICATION FOR COAL

\begin{tabular}{|c|c|c|c|c|}
\hline \multicolumn{2}{|c|}{ Category } & I & II & III \\
\hline \multirow{4}{*}{$\begin{array}{c}\text { Evaluating } \\
\text { indicator }\end{array}$} & Rock burst potentiality & No & Weak & Strong \\
\cline { 2 - 5 } & Dynamic failure time $\left(D_{T}\right) / m \boldsymbol{m}$ & $>500$ & $50<D_{T} \leq 500$ & $\leq 50$ \\
\cline { 2 - 5 } & Elastic energy index $\left(W_{E T}\right)$ & $<2$ & $2<W_{E T} \leq 5$ & $\geq 5$ \\
\hline
\end{tabular}

TABLE II. Rock Burst Potentialities OF ROOF-COAL STRUCTURE Body In DifFerENT Height Ratio [16]

\begin{tabular}{|c|c|c|c|c|c|}
\hline $\begin{array}{c}\text { Height ratio of roof } \\
\text { rock to coal }\end{array}$ & $D_{T} / \mathbf{m s}$ & $K_{E}$ & Elastic energy index & $\begin{array}{c}\text { Uniaxial compressive } \\
\text { strength/MPa }\end{array}$ & Rock burst potentiality \\
\hline $1: 1$ & 166 & 2.82 & 3.92 & 16.28 & Weak \\
\hline $2: 1$ & 12.3 & 9.44 & 5.53 & 19.20 & Strong \\
\hline
\end{tabular}


TABLE III. Rock Burst Potentialities Of Roof-CoAl StRUcture Body In Different Height Ratio [17]

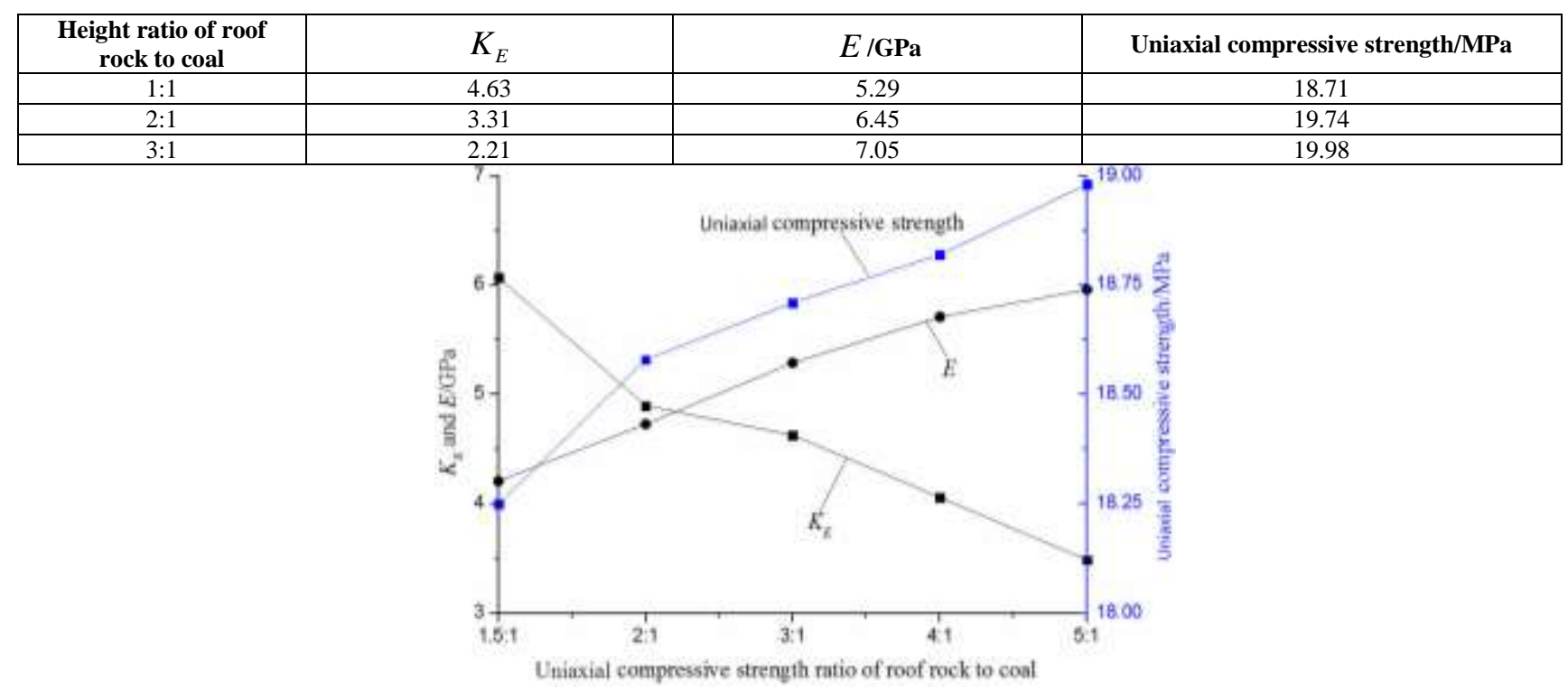

Fig. 4. Relationships between uniaxial compressive strength, $E, K_{E}$, and uniaxial compressive strength ratio of roof rock to coal [17]

In Fig. 2 and Table II and 3, it can be seen that with the increase of height ratio of roof rock to coal, the rock burst potentiality of combined body is enhanced. Especially, in Table II, the combined body with a height ratio of roof rock to coal of 2:1 shows a strong rock burst potentiality. Furthermore, in Table III, $E$ increases with a increase of the height ratio of roof rock to coal.

\section{B. Effect of elastic modulus of rock burst potentiality of combined body}

In Eq. (10), it can be seen that under the same condition, $E$ is positively correlated with the elastic modulus of roof rock or coal. And this means the smaller the elastic modulus of roof rock or coal is, the lower the equivalent elastic modulus is, and the weaker the elastic energy attenuation degree is. And the roof rock-coal combined body rock burst could hardly occur.

Meanwhile, many studies show that the elastic modulus of rock or coal is positively correlated with the uniaxial compressive strength [18-19]. Therefore, there is a positive correlation between uniaxial compressive strength and rock burst potentialities of the roof rock-coal combined body. Fig. 4 gives the relationships between uniaxial compressive strength, $E$ and $K_{E}$ of the roof rock-coal combined body and uniaxial compressive strength ratio of roof rock to coal [17].

In Fig. 4, with the increase of uniaxial compressive strength ratio of roof rock to coal, the uniaxial compressive strength and $E$ of the roof rock-coal combined body increase. Meanwhile, $K_{E}$ decreases with the increase of height ratio of roof rock to coal. And this means that the rock burst potentiality of roof rock-coal combined body is enhanced.

\section{Proposals on PREVEntion of Rock BuRst IN DeEP MINING}

According to the above analysis, the rock burst potentiality of roof rock-coal combined body is affected by the height ratio of roof rock to coal and elastic modulus of roof rock and coal. The height ratio of roof rock to coal is generally determined on working face. Therefore, in order to effectively reduce and prevent the rock burst hazards, many techniques can be adopted to reduce elastic modulus of roof rock and coal, especially the elastic modulus of coal. And these techniques mainly include coal seam infusion, borehole pressure relief in coal and pressure-relieving groove in coal, etc.

\section{CONCLUSIONS}

The rock burst is a dynamic phenomenon of the sudden release of the elastic energy aggregated in the roof rock-coal combined body. The elastic energy attenuation degree can be taken as a evaluation index for the rock burst occurrence for the combined body. And the elastic energy attenuation degree is positively correlated with its equivalent elastic modulus. Meanwhile, the equivalent elastic moduli of the combined body is determined by the height ratio and elastic modulus of roof rock and coal. Generally, the larger the height ratio and elastic modulus of roof rock or coal are, the great the equivalent elastic modulus is and the stronger the elastic energy attenuation degree is. Therefore, rock burst of the roof rock-coal combined body can easily occur. Combining the actual conditions of the coal mine, many techniques can be adopted to reduce elastic modulus of coal for to reduce or prevent the rock burst of combined body, such as coal seam infusion, borehole pressure relief in coal and pressure-relieving groove in coal, etc.

\section{ACKNOWLEDGEMENTS}

This study was supported by the National Natural Science Foundation of China (51474134, 51774194), Shandong Provincial Natural Science Fundation for Distinguished Young Scholars (JQ201612), Major basic 
research projects of Shandong Natural Science Foundation (ZR2018ZC0740), Natural Science Foundation of Shandong Province (no.ZR2016EEB23), Science and Technology Program of Shandong Provience University (no.J15LH02), Taishan Scholar Talent Team Support Plan for Advantaged \& Unique Discipline Areas and Graduate student science and technology innovation project of Shandong University of Science and Technology (SDKDYC180201).

\section{REFERENCES}

[1] Z. H. Zhao, W. M. Wang, C. Q. Dai, and J. X. Yan, "Failure characteristics of three-body model composed of rock and coal with different strength and stiffness," T. Nonferr. Metal. Soc., vol. 24, pp. 1538-1546, 2014

[2] Z. H. Zhao, W. M. Wang, L. H. Wang, and C. Q. Dai, "Compressionshear strength criterion of coal-rock combination model considering interface effect,". Tunn. Undergr. Sp. Tech., vol.47, pp. 193-199, 2015

[3] T. B. Zhao, W. Y Guo, C. P. Lu, and G. M. Zhao, "Failure characteristics of combined coal-rock with different interfacial angles ," Geomech. Eng., vol. 11, pp. 345-359, 2016.

[4] C. P. Lu, G. J. Liu, Y. Liu, N. Zhang, J. H. Xue, and L. Zhang, "Microseismic multi-parameter characteristics of rockburst hazard induced by hard roof fall and high stress concentration," Int. J. Rock Mech. Min., vol. 76, pp. 18-32, 2015.

[5] D. W. Yin, S. J. Chen, X. Q. Liu, and H. F. Ma, "Effect of joint angle in coal on failure mechanical behavior of rock-coal combined body," Q. J. Eng. Geol. Hydroge., vol. 51, pp. 202-209, 2018.

[6] Q. X. Qi, Y. W. Shi, and T. Q. Liu, "Mechanism of instability caused by viscous sliding in rock burst," J. China Soc., vol. 22, pp. 144-148, 1997

[7] J. Q. Li, Q. X. Qi, D. B. Mao, and Y. X. Wang, "Discussion on evaluation method of bursting liability with composite model of coal and rock," Chin. of J. Rock Mech. Eng., vol. 24, pp. 4805-4810, 2005.

[8] C. P. Lu, L. M. Dou, and X. R. Wu, "Experimental research on rules of rockburst tendency evolution and acoustic-electromagentic effects of compound coal-rock samples," Chin. J. Rock Mech. Eng., vol. 26, pp. 2549-2556, 2007

[9] J. P. Zuo, J. L. Pei, J. F. Liu, R. D. Peng, and Y.C. Li, "Investigation on acoustic emission behavior and its time-space evolution mechanism in failure process of coal-rock combined body," Chin. J. Rock Mech. Eng., vol. 30, pp. 1564-1570, 2011.

[10] S. J. Chen, D. W. Yin, B. L. Zhang, H. F. Ma, and X. Q. Liu, "Study on mechanical characteristics and progressive failure mechanism of roof-coal pillar structure body," Chin J. Rock Mech. Eng., vol. 36, pp. $1588-1598,2017$.

[11] B. X. Huang, and J. W. Liu, "The effect of loading rate on the behavior of samples composed of coal and rock," Int. J. Rock Mech. Min., vol. 61, pp. 23-30, 2013.

[12] L. M. Dou, and X. Q. He, Theory and technology of rock burst prevention. Xuzhou: China University of Mining and Technology Press, 2001.

[13] S. Q. Yang, W. Y. Xu, and L. D. Wei, "Statistical constitutive model for rock damage under uniaxial compression and its experimental study,” J. Hohai Univ., vol. 32, pp. 200-203, 2004.

[14] J. M. Yao, F. L. He, J. Xu, and L. M. Dou, "Energy mechanism of rock burst and its application," J. Cent. South Univ, vol. 40, pp. 808813, 2009.

[15] C. P. Lu, "Intensity weakening theory for rockburst of compound coal-rock and its application. Xuzhou: China University of Mining and Technology, 2008.

[16] L. S. Song, S. K. Zhao, J. Liu, X. Z. Wei, R. J. Han, and H. B. Jiang, "Experimental research on rules of rock burst tendency evolution and mechanical properties of "roof-coal" structure body," J. China Coal Soc., vol. 39, pp. 23-30, 2014.

[17] W. J. Guo, H. Zhou, N. H. Xui, W. G. Chen, and P. Wei, "Simulation study of mechanical properties of coal rock combination," Safety Coal Mines, vol. 47, pp. 33-35+39, 2016.

[18] V. Palchik, "On the ratios between elastic modulus and uniaxial compressive strength of heterogeneous carbonate rocks," Rock Mech. Rock Eng., vol. 44, pp. 121-128, 2011.

[19] H. Sonmez, E. Tuncay, and C. Gokceoglu, "Models to predict the uniaxial compressive strength and the modulus of elasticity for Ankara Agglomerate," Int. J. Rock Mech. Min., vol. 41, pp. 717-729, 2004. 